\title{
Millesimal Series of Attenuation
}

National Cancer Institute

\section{Source}

National Cancer Institute. Millesimal Series of Attenuation. NCI Thesaurus. Code C88110.

Preparation of a homeopathic substance with a ratio of one part original material to 1000 parts of carrier or solvent, traditionally lactose, water or ethanol. 